\title{
Zitoeskeletoaren konplexutasuna espermiogenesian
}

\author{
The complexity of the cytoskeleton in spermiogenesis \\ Edurne Alonso Arana eta Maider Bizkarguenaga Uribiarte \\ EHU. Medikuntza eta Erizaintza Fakultatea. Zelulen Biologia eta Histologia Saila. \\ edurne.alonso@ehu.eus
}

\section{Laburpena}

Espermatidaren zitoeskeletoak egitura oso konplexuak eratzen ditu. Egitura iraunkorrak zein iragankorrak izanda, guztien koordinazioa eta elkarlana ezinbestekoa da zelula helduaren garapen morfofuntzionalerako. Espermatida gameto maskulinoa edo espermatozoidearen aurreko zelula mota da. Espermatozoidea zelula oso espezializatua da, hozi-zelulen murrizketa genetiko eta berrantolaketa zitoplasmatiko konplexu baten emaitza. Prozesu bi horien inguruan asko dakigu, meiosiari buruz, bereziki. Baina, zitoplasmaren berrantolaketan, nahiz eta prozesuan parte hartzen duten egitura zitoesletikoak deskribatuta egon, gutxi dakigu haren garraio, polarizazio, eraketa eta elkarren arteko harremanaren inguruan. Mikrotubulu eta mikropiruzko egiturak dira, hots; akrosomaren eraketarako beharrezkoa den sare trans-Golgi, manchette-a, akroplaxoma, buru-isatsa loturarako aparatua eta axonema dira. Guztiak egitura eta mekanismo erabat garrantzitsuak espermatozoide bideragarriak; mugikorrak, ernaltzeko gaiak, eta azkenbatean, beharrezkoak gure espeziaren iraunkortasunerako, alegia.

Ernalezintasuna osasun publikoaren lehentasuna bihurtu da eta haren ikerketa interes handikoa da egun, zientifikoa zein soziala. Gizonezkoen ernalezintasun-kasu gehienak espermatogenesiaren akatsen ondorio dira. Egoera horietan Laguntza Bidezko Ugalketa Teknikak (LBUT) erabiltzen dira eta haien arrakasta espermatozoidearen aukeraketan dago. Gizonezkoaren ernaelezintasun askoren zergatiak ezezagunak direnez eta terapiaren ondorioak LBUT eta hormonen kontrolaren haratago doazenez, zergatien bide asoziatuak eta ernalezintasunean inplikatutako molekulen identifikazioak erabateko garrantzia dauka egun. Espermatogenesiaren azkenengo etapa, non espermatida biribila gameto maskulino funtzionala bilakatzen den, gakoa izan daiteke espermatozoidea aukeratzeko teknikak garatzean. Horren inguruko ezagutza oso tresna erabilgarria izan daiteke LBUTetarako beharrezkoa den gameto maskulinoa aukeratzeko metodoen diseinurako.

Gako-hitzak: espermiogenesia, zitoeskeletoa, akrosoma, akroplaxoma, manchette-a

\section{Abstract}

The spermatid cytoskeleton forms intricate structures. Spermatogenesis is a complicated process that combines proliferation, meiosis and finally differentiation of the haploid cell, called roud spermatid. The last part or this process or spermiogenesis is the transformation of the round spermatid into elongated spermatid by several structural modifications: the biogenesis of the acrosome, the nuclear compaction, the formation of the flagellum, the mitochondrial reorganization and the elimination of almost the entire cytoplasm. The cytoskeleton of the spermatid is key in this total reorganization; a network of microtubules and microfilaments whose assembly, organization and interaction is crucial for obtaining the functional male gamete. These are described structures, but, today, there are many unknown aspects about the transport, polarization, organization and relationship that they establish 
among themselves. They are the trans-Golgi network for the formation of the acrosome, the manchette, the acroplaxoma, the head-tail coupling apparatus (HTCA) and the axoneme of the spermatid. Infertility has become a priority of public health and its study is of huge interest, both scientific and social. Male infertility is due to defective spermatogenesis, caused by one or more failures during the biogenesis of the male gamete. Since assisted reproduction techniques are the most chosen options for cases of male infertility and since in most cases the success of the technique lies in the success of sperm selection, focusing on understanding the pathways associated with the causes themselves, as well as the identification of molecules involved with infertility itself, has become a social priority.

Keywords: spermiogenesis, cytoscheleton, acrosome, acroplaxome, manchette

Bidalia: 2019ko urriaren 7an

Onartua: 2020ko otsailaren 7an

http://doi.org/10.26876/osagaiz.1.2020.274

\section{Sarrera}

Espermatozoidea zelula oso berezia da. Garrantzitsua guztiz, eta gure espezieak jarraipena izan dezan ezinbestekoa. Gameto maskulinoa funtzionala izateko; hau da, bere eginkizuna bete ahal izateko, urrats batzuk igaro behar ditu. Behin meiosia bukatua, beraz, gametoaren oinarri genetikoa den premisa behin ezarrita dagoenean, espermatida deritzon zelula haploideak desberdintzapen-prozesu oso konplikatua du. Haren zitoeskeletoak egitura berezi oso antolatuak eraikitzen ditu. Horietako batzuk egonkorrak (espermatozoidearen isatsa izango den oinarria, esaterako), beste batzuk iragankorrak (manchette-a esaterako), baina mota bien arteko koordinazioa eta elkarlana ezinbestekoa da zelula helduaren morfologiaren eta funtzioaren garapenerako. Gaur egun, egitura horiek deskribatuta daude, baina gutxi dakigu haien garraio, polarizazio, antolakuntza eta haien arteko elkarlanari buruz. Mikrotubuluzko eta mikropiruzko egiturak dira: hain zuzen, akrosoma eratzeko sare trans-Golgi, manchette-a, akroplaxoma, buru-isatsa loturarako aparatua eta axonema. Guztiak beharrezkoak dira espermatozoide bideragarriak lortzeko; hau da, mugikorrak eta ernalgarriak.

Bikoteen \% 15ek ernalezintasun-arazoak ditu, eta horietatik \% 50en arazoa gizonezkoarena da (1). Munduko Osasun Erakundeak (MOE) ernalezintasuna osasun-arazo globala kontsideratzen du, ez soilik mundu-mailako jaiotza-tasa murrizten ari delako, baizik eta seme-alabak izateko arazoak dituzten pertsonen osasun mentalean daukan eraginagatik ere (2). Gaur egun zenbait teknika erabiltzen dira, Laguntza Bidezko Ugalketa Teknikak (LBUT) dira: In vitro ernalketa (IVE) eta espermaren injekzio intrazitoplasmatikoa (ICSI; Intra Cytoplasmic Sperm Injection).

Munduko Osasunaren Erakundearen arabera, hodixka seminiferoetara askatzen diren espermatozoideen \% 85 morfologiaren aldetik akastunak dira eta azpipopulazio horren ezaugarriak adierazgarriak dira espermatozoideak prestatzeko; guztiz esanguratsua, beraz, LBUT metodoen aukeraketan.

Espermatozoideen akats morfologiko eta funtzionalen zergatiak ez daude batere argi gaur egun, espermatozoidearen garapenean diren mekanismo zelular eta molekularren inguruan ezjakintasun handia baitago. Massart et al.-ek estimazio bat egin zuten 2012an (3), non esaten zen giza espermatozoideak garapen zuzena izan dezan 2.300 gene baino gehiago adierazi behar direla. Beraz, espermatogenesi akastuna ernalezintasun maskulinoaren kausarik garrantzitsua dela jakinda, gene horien karakterizazioak oinarrizkoa dirudi prozesu biologiko hau ulertzeko (4).

Espermatogenesiaren azkeneko fasea espermatida biribilaren desberdintzeari dagokio; hots, gameto maskulino funtzionalean eraldatze-prozesua. Azkeneko etapa horrek garrantzi aipagarria dauka gametoa aukeratzeko tekniken hautaketan. Gai horren inguruko ezagutzak tresnak eman ahal dizkigu bai LBUTetarako gameto maskulinoaren aukeraketan, bai ernalezintasuna tratatzeko ere. 
Prozesuaren oinarriak laburbilduko dira hurrengo paragrafoetan, orkestrazio konplikatu eta zehatz hau ulertzeko.

\section{Espermatogenesia eta espermiogenesia}

Espermatogenesia zelulen desberdintze-prozesu bat da (1. irudia). Lerro germinaleko zelula ametatik garatua, haren emaitza zelula haploide oso desberdindu bat da: espermatozoidea. Prozesu konplikatua da, eta hiru prozesu bereiz dakizkioke: mitosia edo proliferazioa, meiosia edo gai genetikoaren murrizketa, eta desberdinzea edo espermiogenesia. Lehenengo fasea epitelio seminiferoaren eremu basalean gertatzen da. Bertan espermatogoniak mitosiz zatitzen dira espermatozito primarioak emanez. Bigarren fasean espermatozito primario diploideek bi zatiketa meiotiko egiten dituzte espermatida biribilak emateko. Azkeneko fasean, morfogenesi konplexua den espermiogenesiari esker, espermatida biribilak espermatida luzeak bilakatuz ezberdintzen dira, espermatozoideen aurrekariak $(5,6)$. Espermatida haploideak hodixka seminiferoaren eremu adluminalean kokaturik daude, Sertoli zelula somatikoen hobitxoetan. Sertoli zelula hodixka seminiferoaren zelula somatiko bakarra da, eta zelula espermatogenikoentzat euskarri estrukturala zein funtzionala da.

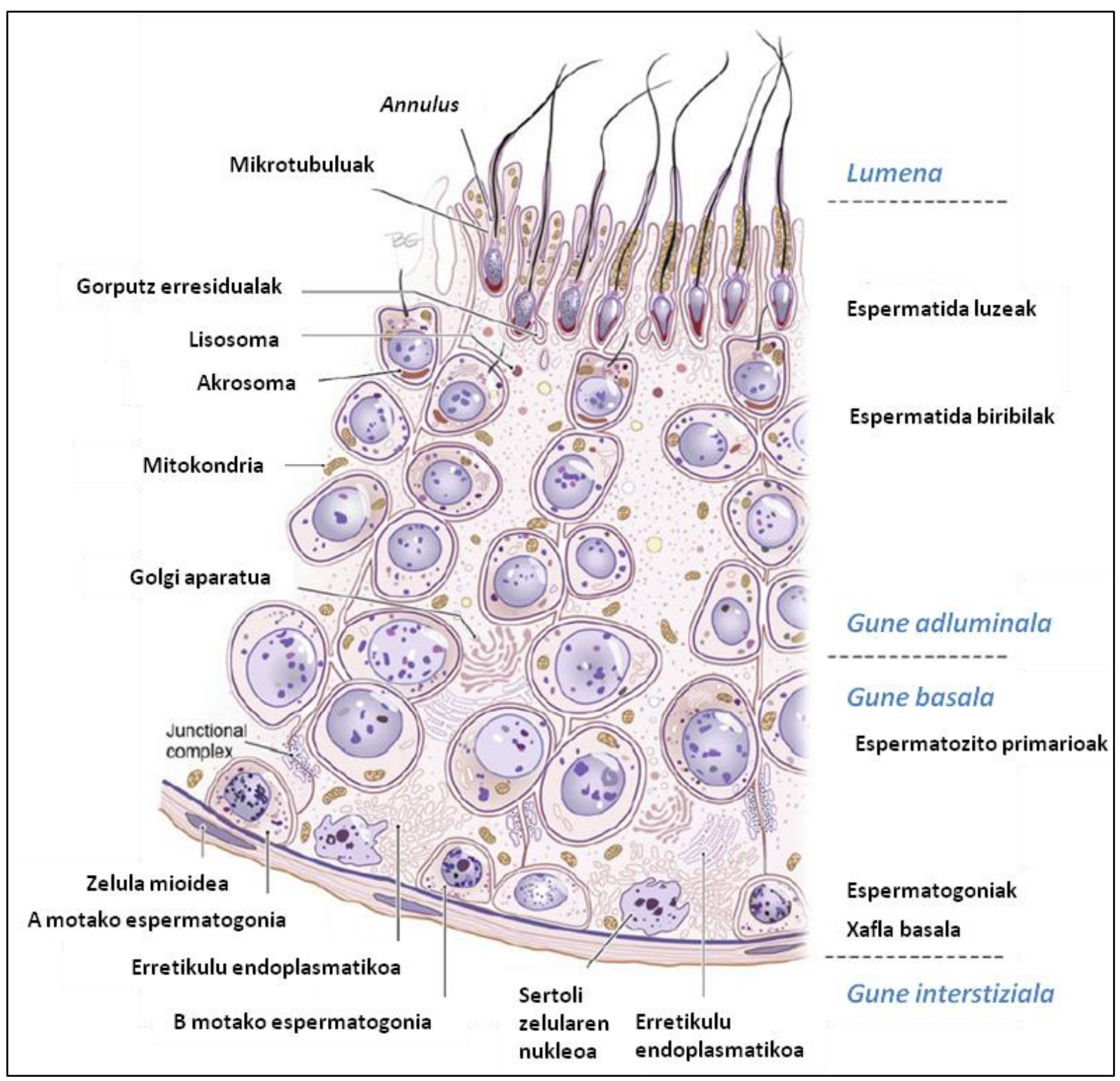

1. irudia. Zelula espermatogenikoen antolaketa epitelio seminiferoan. Epitelio seminiferoak bi gune ditu: gune basala, non espermatogonia eta espermatozito primarioak dauden, eta gune adluminala, zeinek espermatida biribilak eta espermatida luzeak dituen (72). 
Espermatidaren desberdintze-prozesua edo espermiogenesia (2. irudia) hurrengo lau urratsetan oinarriturik dago: akrosomaren biogenesia, manchette-aren eraketa, nukleoaren kondentsazioa eta flageloaren organizazioa. Aldaketa estruktural horiek aldi berean gertatzen dira eta horren emaitza zelula oso espezializatu bat da: espermatozoidea. Espermatozoidean hiru eremu bereizten dira: burua, non nukleoa eta akrosoma dauden; lepoa edo burua eta isatsa konektatzeko atala, eta isatsa, gameto maskulinoari mugimendua ematen dion egitura.

Hurrengo paragrafoetan espermiogenesian gertatzen diren prozesuak azalduko dira.

\subsection{Akrosoma}

Akrosoma zelula espermiogenikoen organulo esklusiboa da. Entzima hidrolitikoak ditu, espermatozoideak obozitoa ernaltzeko beharrezkoak (7). Haren biogenesia zaku akrosomikoan entzima hidrolitikoen sintesi eta metaketa progresiboan datza. Zaku akrosomikoa nukleoaren gaineztadurari lotuta dago zitoeskeletozko egitura bati esker: akroplaxoma. Akroplaxoma aktinazko piruz eta keratina 5-eko piru ertainez osaturik dago (8). Akrosomaren eraketan 4 fase desberdintzen dira:

1.- Golgi fasea. Urrats horretan Golgi aparatutik entzima hidrolitikoak aukeratu eta garraiatu egiten dira, besikuletan metaturik, nukleoaren aurreko aldera. Garraio horretan mikrotubuluetatik doazen proteina motorrek (9) zein aktinazko mikropiruek hartzen dute parte. Besikulen fusioaren ondorioz zaku akrosomikoa sortzen da.

Aldi berean, kontrako polora zentrioloen migrazioa gauzatzen da, nukleoaren atzeko aldera, hain zuzen. Zentriolo distala axonemaren eraketaz arduratzen da, hots flageloaren oinarri estrukturala; eta zentriolo proximalak eta matrize perizentriolarrak burua eta isatsa lotzeko egitura eratuko dute. Gertaera hauek espermatida biribilen lehenengo faseetan gertatzen dira.

2.- Txano fasea. Fase honetan zaku akrosomikoa zapaldu egiten da eta txano antzeko egitura bat eratzen du nukleoaren gaineztadurari itsatsita. Lotura horri, F-aktina, keratina 5 eta beste proteina batzuez osaturik dagoena, akroplaxoma deritzo (8) edo akrosomaren azpiko leka (subacrosomic layer; SAL) (10). Bitartean, axonemaren hazkuntzak aurrera egiten du.

3.- Fase akrosomikoa. Fase horretan zehar, akrosomak, nukleoaren gaineztadurari itsatsita, atzeko polorantz jarraitzen du bere hazkuntza. Urrats horretan zelularen elongazioa gertatzen da, apurka espermatozoidearen morfologia luzanga berezia jabetuz. Espermiogenesiaren une horretan material genetikoaren konpaktazioa ere hasten da, non histonak protaminekin ordezkatuko diren. Espermatidaren buruaren elongazioa zitoeskeletozko egitura berezi batzuei esker gertatzen da, espermiogenesiaren esklusiboak diren akroplaxoma eta manchette-a (11).

4.- Azkenik, heldutasun-fasea espermatidaren azkenengo estadioei dagokie. Akrosomak nukleoaren aurreko gaineztadura osoa estaltzen du. 


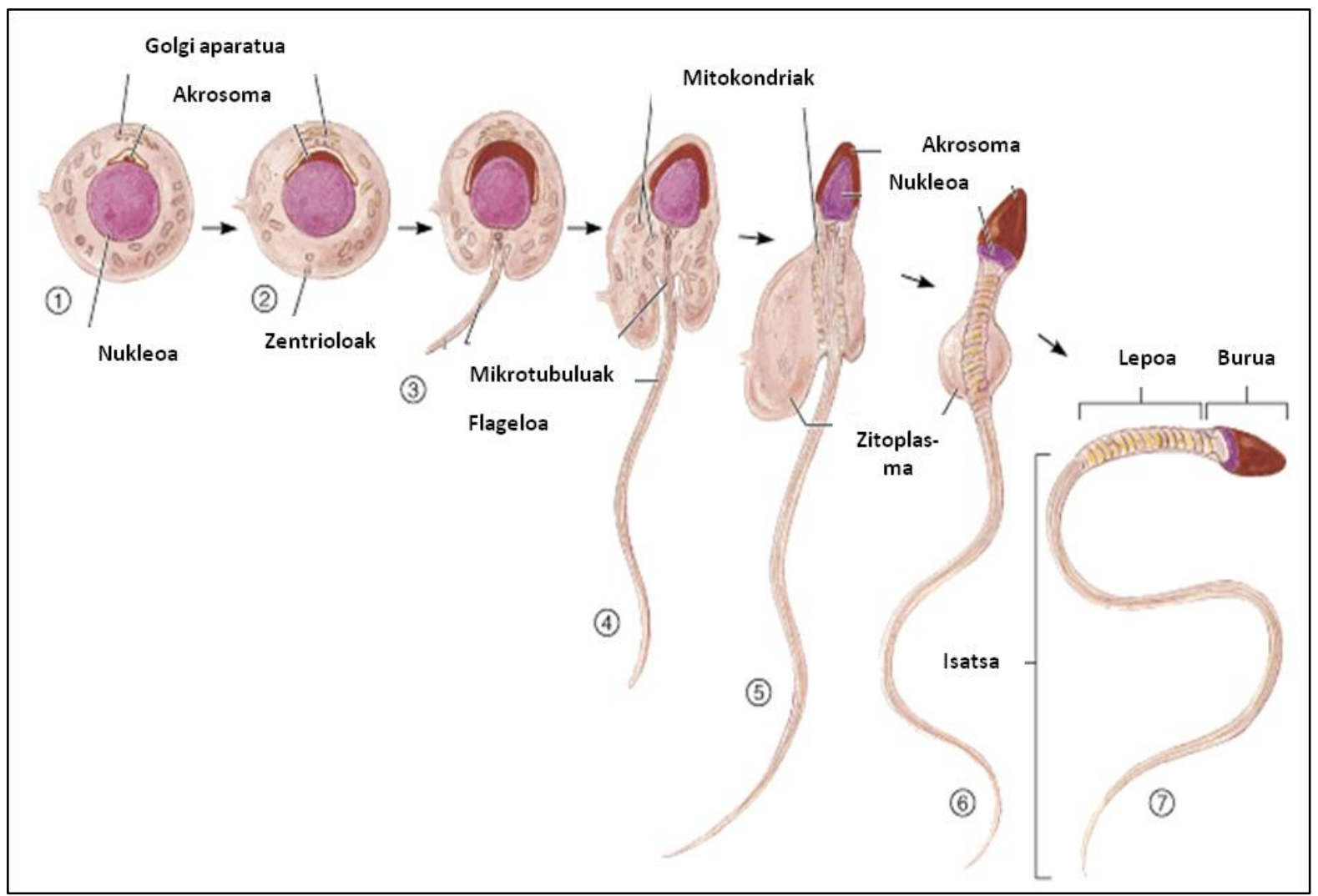

2. irudia. Espermiogenesiaren urratsak. Espermatida biribilen (1 eta 2 ) luzaketa progresiboa ( 3 eta 4), bitarteko espermatida luzeak (5 eta 6 ) eta, azkenik, espermatozoide helduak (7) izateko beharrezkoa den desberdintzapen-prozesua edo espermiogenesia adierazten du irudiak (73).

\subsection{Manchette-a}

Manchette-a mikrotubuluzko egitura iragankorra da eta espermiogenesirako beharrezkoa den garraio oso hertsiki antolatu batez arduratzen da. Gai nuklearrak $(12,13)$ zein zitoplasmatikoak garraiatzen ditu $(12,14,15,16)$. Manchette-a axonemaren garapena hasita dagoenean eratzen da eta espermiogenesia bukatzear dagoela desmontatu egiten da, behin espermatidaren nukleoaren elongazioa eta kondentsazioa kasik burututa daudenean $(16,17,18)$.

Espermatidaren elongazioak beste egitura atxiki batzuen presentzia behar du: akroplaxomaren bazterreko eraztuna eta manchette-aren eraztun perinuklearra. Lehenengoa bai nukleoari bai akrosomari lotuta dago eta axonema aldera atzeratzen da, nukleoaren elongazioa eraginez. Bigarrenak, nukleoaren inguruan kokatuta, bere diametroa murriztuz doa eta beste eraztunarekin batera axonema aldera mugitzen da (11). Sertoli zelulen aktinazko piruek sortutako indarrek ere elongaziorako ezinbestekoak dira.

\subsection{Gai genetikoaren kondentsazioa}

Espermiogenesian ere kromatinaren kondentsazio-maila aldatzen da. Kromosomak paketatzeko beharrezkoak diren histonak argininan eta lisinan aberatsak diren beste proteina nuklear batzuekin ordezkatzen dira; protaminak deritze. DNAren antolaketa berezi honek espermatozoidearen nukleo ñimiñoan DNA egonkor eta kondentsatua mantentzea ahalbidetzen du. Espermatida biribilen histonak barrabilaren espezifikoak diren histonekin ordezkatzen dira, geroago trantsiziozko proteinekin eta protaminekin azkenik $(14,19)$. Proteina basiko horiekin lortzen den paketazio-maila gorena da. Histonekin DNAk duen solenoide forma, protaminekin toroidala izango du (20). 


\subsection{Flageloa}

Espermatozoidearen isatsa edo flageloa axonematik eratzen da nukleoaren eremu distalean, akrosomaren aurkako poloan, hain zuzen. Axonemaren gainetik Outer dense fiber proteins (ODFs)-k osatutako zuntz dentsoek espermatidaren buruaren eta isatsaren arteko lotura osatzen dute. Mitokondriak eremu horretara garraiatu eta helikoidalki zuntz dentsoen inguruan antolatzen dira, isatsaren tarteko pieza osatuz. Zuntz dentsoak eta leka zuntzduna edo fibrosoa egitura proteikoa flagelotik luzatzen dira, pieza nagusia eta bukaerako zatia osatuz (21).

Espermiogenesiaren bukaerarako beste gertaera batzuk aipatu behar dira: manchette-aren desantolaketa (behin nukleoa guztiz elongatuta dagoenean), zitoplasmaren gehiengoaren exozitosia (Sertoli zelulek fagozitatua izango dena), kromatinaren kondentsazioaren bukaera (ordutik transkripzioa erabat murriztua egongo da) eta mitokondrien lerrokatzea. Emaitza, espermatozoidearen morfologia duen zelula luzanga da, alegia.

Gertaera hauetako aldaketa estrukturalak (akrosomaren eraketa, nukleoaren kondentsazioa, flageloaren antolaketa eta zitoplasmaren berrantolaketa) ondo deskribatuak egon arren, asko falta da zehaztasunez azaltzeko gameto maskulinoaren garapenaren azkeneko urrats honetan gertatzen diren prozesu molekularrak (22).

\section{Zitoeskeletoaren garrantzia espermiogenesian: leka perinuklearra, akroplaxoma, manchette-a}

Espermatida biribilek aldaketa estrukturalak pairatzen dituzte espermatozoidearen forma luzeko zelula bilakatzeko. Aldaketa horietan zitoeskeletozko egitura esklusiboek hartzen dute parte, espermatidarenak esklusiboak.

\subsection{Leka perinuklearra}

Leka perinuklearra (LP) nukleoaren gaineztaduraren gehiengoa (isatsaren inplantazio-unea salbu) estaltzen duen leka fibroso elektrodentsoa da (23). Espermatidaren buruaren zitoeskeletozko egitura printzipala da eta proteina zitosolikoz eta nuklearrez osatuta dago. Eremu apikalean, leka azpiakrosomikoa (SubAcrosomic Layer, edo SAL) osatuz, akrosomaren barru aldeko mintzaren eta mintz nuklearraren artean dago. Eremu kaudalean, akrosomaren bukaeratik eta lotura piezaren arteko kokapenarekin, mintz plasmatikoaren eta mintz nuklearraren artean aurkitzen da, leka postakrosomikoa deritzolarik (PostAcrosomal Sheath, ó PAS) $(10,24)$.

Zelularen mintz guztiak Triton detergentearekin degradatzen dira, LPa izan ezik. Tripsinak edo SDSak erabili behar dira gaineztadura hau desantolatzeko $(25,26)$. Detergente ez-ionikoen bidez LPa isolatu daiteke, haren osaketa proteikoa ateratzeko $(27,28)$. LParen proteinak erauzteko, $1 \mathrm{M} \mathrm{NaCl}$ eta 100 $\mathrm{mM} \mathrm{NaOH}$-ko urrats sekuentzialek osagaien banaketa baimentzen dute SDS-page batean.

LParen atzeko eremuan edo PASen PAWP proteina aurkitu da. Proteina hori SOAF (Sperm Oocyte Activating Factor) proposatua izan da $(29,30)$. SOAF definizioz proteina bat da, zeinek gametoen fusio-unean oozitoan $\mathrm{Ca}^{2+}$-aren gorakada induzitzen duen. $\mathrm{Ca}^{2+}$-aren oszilazioa beharrezkoa da enbriogenesiari hasiera emateko. Proteina horrek bi baldintza bete behar ditu: zitoeskeletoan ainguratuta egotea eta espezifikoki LPan (Amdani et al., 2015-en berrikusita) (32). Gaur arte

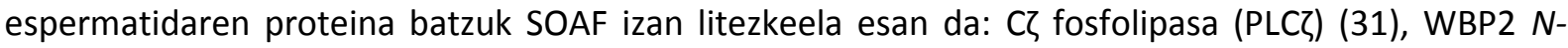
terminal like (WBP2NL edo PAWP) (32). PLÇa LParen eremu akrosomikoan, ekuatorialean eta PASen detektatu da $(31,67,68,69,70,71)$. PAWP, berriz, soilik PASen aurkitu da $(29,30)$. Proteina biek SOAF izateko ezaugarriak dituzte. Lagin oligoastenoteratozoospermikoetan (espermatozoide gutxiko lagina, morfologikoki akastuna eta mugimenduan murriztua) PLC eta PAWP adierazten zituten espermatiden portzentajea txikiagoa zela ikusi zen, baita ere PLÇaren kokapen-patroietan aldaketak. Emaitza hauekin ondorioztatzen da PLCל eta PAWP eskasiak ernalezintasun maskulinoarekin zerikusia izan dezakeela (33). 
LParen aurreko eremua edo SALa egitura jarraitua da, bai estrukturalki, bai osaketari dagokionez. Kierszenbaum doktorearen taldeak akroplaxoma deritzo SALari (8). F-aktinazko leka zitoeskeletikoa da eta desmosomen antzeko (Sak57/K5) keratina duen eraztun marjinal bat. Akrosomaren garapena egonkortzen du, espermatidaren nukleoaren mintzean ainguratzen baitu haren elongazioa sustatuz. Hemendik aurrera SAL egiturari akroplaxoma deituko zaio, egitura bera baita.

\subsection{Akroplaxoma}

Akroplaxoma zitoeskeletozko egitura bik osatzen dute: akroplaxomaren xafla eta eraztun marjinala. Akroplaxomaren xafla nukleoaren aurreko eremuan dago kokaturik nukleoaren mintzaren eta akrosomaren barru aldeko mintzaren artean. Linker of Nucleoskeleton and Cytoskeleton Complex (LINC) egitura proteikoak akrosoma nukleoan ainguratu eta lotzeko funtzioa dauka espermatidaren luzatze-prozesuan zehar $(13,15)$. Eraztun marjinalak eremu ekuatorialeko ingurunean barruko mintz akrosomikoa eta nukleoaren mintza lotzen ditu, akrosomaren garapen-prozesuan zehar betiere nukleoaren mintzari lotuta mantentzeko $(8,11,13)$. Orduan, akroplaxomari funtzio bi dagozkio. Alde batetik, besikulen garraio eta fusioarekin erlazionatuta dagoena, besikula akrosomikoaren eraketan akroplaxomaren xafla hasiberriarekin ainguratzeko. Eta bestetik, Sertoli zelulen aktinazko plaken presioa modulatuz, espermatidaren nukleoa besarkatzen du haren elongazioa eraginez $(8,34,35)$.

Aurretik aipatutako funtzio estrukturalez gain, akroplaxomak ere nukleoaren mintza egonkortu eta babesten du akrosomaren hazkuntza-prozesuan zehar (36,37): akroplaxomaren eremuko xafla dentsoek eta asoziatutako zitoeskeletoak nukleoaren mintza eta akrosomaren lotura hertsia egonkortu egiten baitute (11). Beste ikerketa batzuen arabera, espermatozoidearen mugimenduari direkzioa ere ematen dio, obozitoarekiko fusio-prozesuetan inplikaturik dago bai eta ernalketa osteko espermatidaren deskondentsazioan ere (38).

Egitura honen osaketa proteikoa anizkoitza da. Akroplaxomaren xaflak zitoeskeletozko proteinak ditu, espermatozoidearen buruaren zein nukleoaren gaineztaduraren arkitektura mantentzeko; hau da egonkortasunerako beharrezkoak. PERF 15 akrosomaren mintzari egonkortasuna ematen dio $(39,40)$ eta RAB2A proteinak akrosoma-nukleoaren arteko lotura egonkortzen du (28). Baina proteina zitosolikoz ere dago osatuta. Ernalketarekin zerikusia duten proteinak $(32,37)$ eta histona somatikoak: H2A, H2B, H3 eta H4 $(41,42)$.

\subsection{Manchette-a}

Manchette-a mikrotubuluzko eta aktina-piruzko egitura iragankorra da. Espermatidaren nukleoa besarkatzen du bere luzatze-prozesuan zehar. Mikrotubulu batzuek nukleoa inguratzen duen eraztun perinuklearra eratzen dute eta beste batzuk eraztun horri ainguraturik, zentrosomara bideratuta daude $(8,11)$. Manchette-aren eraketa eta lokalizazio zuzenak ezinbestekoak dira nukleoa luzatzeko, egitura hauek barik ezin baita espermatidaren burua luzatu (43). Antolatu eta desantolatzen da modu oso zehatz batean: elongazio-prozesua hasten denean espermatidan agertzen da eta espermatidaren nukleoa kondentsatua eta luzatuta dagoenean desmontatu egiten da $(14,16,44)$.

Ez dago deskribatuta nola eratzen den manchette-a. Soilik proposatu da bere eraketarako mikrotubulu-zentro antolatzailea (MicroTubule-Organizing Center; MTOC) behar izatea. $\nu$-tubulinaz eratutako zentrosoma izango litzateke, edo eraztun perinuklearra (45), nahiz eta $\gamma$-tubulinazko unitaterik ez eduki (46). Petry-ren taldeak (2013) (47) nukleazioa mikrotubuluak dauden guneetatik hastea proposatu zuen baita ere. Zentrobin mikrotubuluen nukleazio eta estabilizaziorako ezinbestekoa den proteina, zentrosoman egoteaz gain, espermatidaren beste gune batzuetan ere lokalizatu egin da: akroplaxoman, eraztun perinuklearrean eta manchette-an $(48,49)$. Gaur arte, manchette-aren eraketa nondik eta nola hasten den ez dago argi. Eraztun perinuklearrak, zentrosomak edo zitoplasmako mikrotubuluek hasiko zuten eraikuntza hori. Lethi eta Sironen-ek (2016) (16), aurretiko emaitzetan oinarriturik $(35,50)$, non mikrotubuluen - muturra zentrosoman dagoen eta + muturra eraztun perinuklearrean, nukleazioa zentrosomatik eraztun perinuklearrera arte osatzen dela proposatzen dute. Modu horretan, eraztun perinuklearra ez da nukleaziorako ezinbestekoa, baina egitura egonkortzen du eta horrela manchette-a berari ainguratuta mantentzen da. Horrek azaltzen du egituraren garrantzia manchette-aren eraketa egokirako.

Osagaiz - $2020-4$. bolumena - 1. zk. -13 


\subsection{Garraio intrazitoplasmatikoa espermatidaren berrantolakuntzan}

Mikrotubuluak espermatidaren osagai zitoeskeletikoetatik garrantzitsuenetarikoak dira eta ezinbestekoak zelula mota horrek pairatzen dituen aldaketa morfologikoetarako. Akrosoma, manchette-a eta flageloaren oinarri estrukturala eta funtzionala mikrotubuluzko zitoeskeletoa da eta egitura horietako mikrotubuluak garraiobideak dira, funtzio dinamikoak, mekanikoak zein seinaleztapenarekin erlazionaturikoak bete daitezen. Horrela, espermiogenesian zehar garraio mota desberdinak bereizten dira: garraio pre-akrosomikoa trans-Golgi saretik akrosomara, manchette-an zeharreko garraioa (IMT; IntraManchette Transport) eta flageloaren barneko garraioa (IFT; IntraFlagellar Transport). Mikrotubuluzko eraikuntza honen ezartze eta mantenimenduak kontrol oso hertsia behar du, gaur arte ezezaguna dena, alegia.

MAPak (Microtubule Asociated Proteins) tubulinekin parte hartzen duten proteinak dira. Haien funtzioa erregulatu eta garraioa modulatzen dute. Proteina motorrak, dineinak eta kinesinak ere MAP kontsideratu daitezke, baina orokorrean haien izen propioa erabiltzen da izendatzeko. Barrabilean MAP batzuk aurkitu dira, printzipioz manchette-a eratzen duen mikrotubuluzko sarearekin erlazionaturik. Gehienek isatserako garraioarekin eta garraio nukleo-zitoplasmatikoarekin zerikusia dute. Aurkitutakoen artean, TAU (51, 52), MAP4 (53), GMAP210 (35), EMAP115 (54), MAST205 (55), HOOK 1 eta HOOK 2 (56), NUDEL (57), ODF1 (58), SPEM1 (59) eta lehen aipatutako dineina eta kinesina $(16,60,64)$ daude. Asko konplexuetan batuta daude. Konplexu oso garrantzitsuak espermatidaren elongaziorako, RIM-BP3/HOOK1/KIF3B, SPEM1/UBQLN1/RANBP17 (64,65), esaterako.

\subsection{Akrosoma-akroplaxoma-manchette konplexua}

"Burua-itsatsa akoplatzen duen aparatua" edo HTCA (sperm Head-Tail Coupling Apparatus) beharrezkoa da elongatzen ari den espermatidaren burua eta axonema egokitzeko eta IMTa eta IFTa bateratzeko $(35,66)$. Aipatutako egitura hori mikrotubulu eta beste osagai batzuez osaturik dago eta haren garapenerako ezinbestekoa dirudi akrosoma-akroplaxoma-manchette aparatuak. Espermatiden polaritatea HTCA eta akrosoma-akroplaxomaren nukleoarekiko aurrez aurreko posizioak determinatzen du. Espermatidaren buruaren elongazioan, egitura biak (akroplaxoma eta manchette-a) hertsatzaile endogeno moduan aritzen dira, ondorioz eraztun bik (akroplaxomaren eraztun marjinalak eta eraztun perinuklearrak) espermatidaren elongazioa bera zuzentzen dute. Hau guztia kinesina 2 proteinaren ardurapean dagoela proposatu da (16).

Modu horretan, akrosoma, akroplaxoma eta manchette-a konplexu bateratu baten moduan aritzen dira espermatidaren luzatze-prozesuan zehar. Akroplaxomaren eraztun marjinala axonema aldera jaisten da eta horrek nukleoaren eta akrosomaren elongazioa eragiten du, bietara lotuta baitago. Manchette-aren eraztun perinuklearraren diametroa murriztuz doa beste eraztunarekin batera axonema aldera ere jaisten den bitartean. Bestalde, HTCAren aurrez aurreko posizioak espermatidaren buruaren antolakuntza determinatzen du.

Garraioari dagokionez, hiru garraiobide deskribatu dira espermiogenesiaren prozesuan: trans-Golgitik akrosomarako garraiobidea, IMTa eta IFTa. Osagaiak eta ezaugarriak konpartitzen dituzte (mikrotubuluzko eta aktinazko zitoeskeletozko eraikuntzak) eta hiruren artean espermatidaren burua berrantolatzen dute. Ezinbestekoak dira espermatozoidea den zelula oso espezializatu honen morfogenesi eta funtzio egokirako. Manchette-an zehar besikula ez-akrosomikoen eta nukleoaren elongaziorako eta flageloaren eraketarako beharrezkoak diren proteinen IMTa egiten da $(11,12,14)$. Nukleoaren eta zitoplasmaren arteko garraioak noranzko apikal-basal bikoitza azaltzen du. Proteinen garraio eta besikula ez-akrosomikoen garraiorako honako egiturak azaldu dira: aktinazko piruak, miosina-Va eta miosina-VIla proteina motorrei asoziatuta, eta mikrotubuluzko sarea, kinesinari asoziatuta (+ muturrerako garraioan) eta dineinari asoziatuta (- muturrerako garraioan) $(8,61)$.

Garraioan zein antolaketan, hainbat molekula identifikatu dira. GMAP210 eta IFT88 proteinak akrosomaren biogenesi egokiarekin inplikaturik daudela dirudi (35). Manchette-an ere Ran-GTPasa 
makineria aurkitu da $(12,14,35)$, poroaren konplexuetan zeharreko nukleo-zitoplasmaren arteko garraioan dihardu. KIFC1 kinesina, Ran-GTPasaren kontrolpean, akroplaxomaren xaflako mikrotubuluetan zein manchette-arenean lokalizatu egin da (60), baita NUP62 nukleoporinari asoziatua ere $(16,62)$.

Besikulen eta proteinen garraioa manchette-aren mikrotubuluetatik hasi (IMT) eta flageloaren mikrotubuluetatik (IFT) jarraitzen du. Proteina horien artean ODFak daude, flageloaren eraketarako beharrezkoak (61). Garraio horiek biek antzerakoak dirudite eta kinesina eta dineina proteina motorrei esker gertatzen dira $(14,16,35,61,63)$. Beste ezaugarri interesgarri bat ere partekatzen dute: axonema eta manchette-a mikrotubuluek itzulpenaren ostean eraldatuak izan diren tubulina azpiunitate ugariko egiturak dira (35).

\section{Ondorioak}

Espermatidaren zitoeskeletozko sarea ikertzeari lehentasuna eman beharko litzaioke. Ezjakintasun handia dago gameto maskulinoaren garapenerako ezinbestekoak diren mikrotubuluzko eta aktinazko zitoeskeletozko egiturei buruz; garraio, polarizazio eta orokorrean haren antolakuntzari buruz gutxi dakigu eta espermatidaren eraldaketa morfofuntzionalaren oinarria dira, alegia. Nahiz eta MOEren aburuz epididimora heltzen diren espermatozoideen \% 85 akastunak izatea normala izan, gaur egungo ernalezintasun-tasa handiak direla-eta, ezinbestekoa bihurtu da morfogenesi konplikatu horren mekanismo molekularrak ulertzea. Espermatozoidearen garapen-prozesuan egitura horien arteko koordinazioa zein den eta nola egiten den ulertzeko beharra dago. Izatez, ernalezintasun maskulino asko garraio intrazelular akastun batekin erlazionaturik daude, beraz, egitura horiek ondo deskribatzeak ernalezintasuna tratatzeko bideak ireki ditzake edota LBUTetarako gameto maskulinoen aukeraketarako abantaila.

\section{Erreferentzia bibliografikoak}

1. Esteves SC, Miyaoka R, Agarwal A.Sperm retrieval techniques for assisted reproduction. Int Braz J Urology. 2011;37(5):570-83.

2. Van der Poel, SZ. Historical Walk: The HRP Special Programme and Infertility. Gynecol Obstet Invest. 2012;74:218-227.

3. Massart A, Lissens W, Tournaye H, Stouffs K. Genetics causes of spermatogenic failure. Asian J Androl. 2012;14:40-48.

4. Zhang $Y$, Zhong L, Xu B, Yang Y, Ban R, Zhu J, Cooke HJ, Hao QM, Shi Q. SpermatogenesisOnline 1.0: a resource for spermatogenesis based on manual literature curation and genome-wide data mining. Nucleic Acids Res. 2013;41:1055-1062.

5. Oakberg EF. A description of spermiogenesis in the mouse and its use in analysis of the cycle of the seminiferous epithelium and germ cell renewal. Am J Anat. 1956; 99(3):391-413.

6. Fawcett DW. The mammalian spermatozoon. Dev Biol. 1975;44:394-436.

7. Berruti G, Paiardi C. Acrosome biogenesis: Revisiting old questions to yield new insights. Spermatogenesis. 2011 Api;1(2):95-98.

8. Kierszenbaum AL, Rivkin E, Tres LL. Acroplaxome, an F-actin-keratin-containing plate, anchors the acrosome to the nucleus during shaping of the spermatid head. Mol Biol Cell. 2003 Aza;14(11):4628-4640.

9. Moreno RD, Palomino J, Schatten G. Assembly of spermatid acrosome depends on microtubule organi-zation during mammalian spermiogenesis. Dev Biol. 2006 Mai 1;293(1):218-227.

10. Oko RJ. Developmental expression and possible role of perinuclear theca proteins in mammalian spermatozoa. Reprod Fertil Dev. 1995;7(4):777-797.

11. Kierszenbaum AL, Tres LL. The acrosome-acroplaxome-manchette complex and the shaping of the spermatid head. Arch Histol Cytol. 2004 Aza;67(4):271-284. 
12. Kierszenbaum AL, Gil M, Rivkin E, Tres LL. Ran, a GTP-binding protein involved in nucleocytoplasmic transport and microtubule nucleation, relocates from the manchette to the centrosome regionduring rat spermiogenesis. Mol Reprod Dev. 2002 Ira;63(1):131-140.

13. Göb E, Schmitt J, Benavente R, Alsheimer M. Mammalian sperm head formation involves different polarization of two novel LINC complexes. PLoS One, 2010 Abu 10;5(8):e12072.

14. Kierszenbaum AL. Intramanchette transport (IMT): managing the making of the spermatid head, centrosome, and tail. Mol Reprod Dev. 2002 Ira;63(1):1-4.

15. Kierszenbaum AL, Rivkin E, Tres L. Cytoskeletal track selection during cargo transport in spermatids is relevant to male fertility. Spermatogenesis. 2011 Uzt;1(3):221-230.

16. Lehti MS, Sironen A. Formation and function of the manchette and flagellum during spermatogenesis. Reproduction. 2016 Api;151(4):R43-54.

17. Matsuoka Y, Miyagawa Y, Tokuhiro K, Kitamura K, Iguchi N, Maekawa M, Takahashi T, Tsujimura A, Matsumiya K, Okuyama A, Isolation and characterization of the spermatid-specific Smrp1 gene encoding a novel manchette protein. Mol Reprod Dev. 2008 Eka;75(6):967-975.

18. Kierszenbaum AL, Tres LL. Histology and Cell Biology: An Introduction to Pathology, 4th Edition. Philadelphia: Elsevier Saunders; 2015. 752 or.

19. Braun RE. Packaging paternal chromosomes with protamine. Nat Genet. 2001 Mai;28(1):10-12.

20. Allen MJ, Lee C, Lee IV JD, Pogany GC, Balooch M, Siekhaus WJ. Atomic force microscopy of mammalian sperm chromatin. Chromosoma. 1993 Aza;102:623-630.

21. Toshimori K, Eddy EM. The spermatozoon. Hemen: Knobil and Neill's Physiology of Reproduction. Plant T, Zeleznik A, editors. Cambridge:Academic Press, Elsevier; 2015. pp. 99-148.

22. Borg CL, Wolski KM, Gibbs GM, O’Bryan MK. Phenotyping male infertility in the mouse: how to get the most out of a 'non-performer'. Hum Reprod Update. 2010 Mar-Api; 16(2): 205-224.

23. Courtens JL, Courot $M$, Flechon JE. The perinuclear substance of boar, bull, ram and rabbit spermatozoa. J Ultrastruct Res. 1976 Urr;57(1):54-64.

24. Oko RJ, Sutovsky P. Biogenesis of sperm perinuclear theca and its role in sperm functional competence and fertilization. J Reprod Immunol. 2009 Abe;83(1-2):2-7.

25. Perry AC, Wakayama T, Yanagimachi R. A novel trans-complementation assay suggests full mammalian oocyte activation is coordinately initiated by multiple, submembrane sperm components. Biol Reprod. 1999 Mar;60(3):747-755.

26. Perry AC, Wakayama T, Cooke IM, Yanagimachi R. Mammalian oocyte activation by the synergistic action of discrete sperm head components: induction of calcium transients and involvement of proteolysis. Dev Biol. 2000 Urt 15;217(2):386-393.

27. Oko R, Maravei D. Protein composition of the perinuclear theca of bull spermatozoa. Biol Reprod. 1994 Mai;50(5):1000-1014.

28. Mountjoy JR, Xu W, McLeod D, Hyndman D, Oko R. RAB2A: a major subacrosómica protein of bovine spermatozoa implicated in acrosomal biogenesis. Biol Reprod. 2008 Abu;79(2):223-232.

29. Wu AT, Sutovsky P, Manandhar G, Xu W, Katayama M, Day BN, Park KW, Yi YJ, Xi YW, Prather RS, Oko R. PAWP, a sperm-specific WW domain-binding protein, promotes meiotic resumption and pronuclear development during fertilization. J Biol Chem. 2007 Api 20;282(16):12164-12175.

30. Aarabi M, Balakier H, Bashar S, Moskovtsev SI, Sutovsky P, Librach CL, Oko R. Sperm content of postacrosomal WW binding protein is related to fertilization outcomes in patients undergoing assisted reproductive technology. Fertil Steril. 2014 Abu;102(2):440-447.

31. Aarabi M, Yu Y, Xu W, Tse MY, Pang SC, Yi YJ, Sutovsky P, Oko R. The testicular and epididymal expression profile of PLCZ in mouse and human does not support its role as a sperm-borne oocyte activating factor. PLoS One. 2012;7(3):e33496.

32. Amdani SN, Yeste M, Jones C, Coward K. Sperm Factors and Oocyte Activation: Current Controversies and Considerations. Biol Reprod. 2015 Abu;93(2):50.

33. Azad N, Nazarian H, Ghaffari-Novin M, Masteri-Farahani R, Piryaei A, Heidari MH, AbdollahpourAlitappeh M. Oligoasthenoteratozoospermic (OAT) men display altered phospholipase C $\zeta$ (PLCZ) localization and a lower percentage of sperm cells expressing PLC and post-acrosomal sheath WW domain-binding protein (PAWP). Bosn J Basic Med Sci. 2018 Mai 20;18(2):178-184. 
34. Kierszenbaum AL, Rivkin E, Tres LL. Molecular biology of sperm head shaping. Soc Reprod Fertil Suppl. 2007;65:33-43.

35. Kierszenbaum AL, Rivkin E, Tres LL, Yoder BK, Haycraft CJ, Bornens M, Rios RM. GMAP210 and IFT88 are present in the spermatid golgi apparatus and participate in the development of the acrosome-acroplaxome complex, head-tail coupling apparatus and tail. Dev Dyn. 2011 Mar;240(3):723-736.

36. Sutovsky P, Oko R, Hewitson L, Schatten G. The removal of the sperm perinuclear theca and its association with the bovine oocyte surface during fertilization. Dev Biol. 1997 Abu 1;188(1):75-84.

37. Sutovsky P, Manandhar G, Wu A, Oko R. Interactions of sperm perinuclear theca with the oocyte: implications for oocyte activation, anti-polyspermy defense, and assisted reproduction. Microsc Res Tech. 2003 Uzt 1;61(4):362-378.

38. Mújica A, Navarro FG, Hernández G, Juárez M ML. Perinuclear theca during spermatozoa maturation leading to fertilization. Microsc Res Tech. 2003 Mai 1;61(1):76-87.

39. Oko R, Morales CR. A novel testicular protein, with sequence similarities to a family of lipid binding proteins, is a major component of the rat sperm perinuclear theca. Dev Biol. 1994 Aza;166(1):235-245.

40. Korley R, Pouresmaeili F, Oko R. Analysis of the protein composition of the mouse sperm perinuclear theca and characterization of its major protein constituent. Biol Reprod. 1997 Abe;57(6):1426-1432.

41. Aul RB, Oko RJ. The major subacrosómica occupant of bull spermatozoa is a novel histone H2B variant associated with the forming acrosome during spermiogenesis. Dev Biol. 2002 Ots 15;242(2):376-387.

42. Tovich PR, Oko RJ. Somatic Histones Are Components of the Perinuclear Theca in Bovine Spermatozoa. J Biol Chem. 2003 Abu 22;278(34):32431-3248.

43. Russell LD, Russell JA, MacGregor GR, Meistrich ML. Linkage of manchette microtubules to the nuclear envelope and observations of the role of the manchette in nuclear shaping during spermiogenesis in rodents. Am J Anat. 1991 Urr;192(2):97-120.

44. Toshimori K, Ito C. Formation and organization of the mammalian sperm head. Arch Histol Cytol. 2003 Abe;66(5):383-396.

45. Wolosewick JJ, Bryan JH. Ultrastructural characterization of the manchette microtubules in the seminiferous epithelium of the mouse. Am J Anat. 1977 Urr;150(2):301-331.

46. Moreno RD, Schatten G. Microtubule configurations and post-translational $\alpha$-tubulin modifications during mammalian spermatogenesis. Cell Motil Cytoskeleton. 2000 Abu;46(4):235-246.

47. Petry S, Groen AC, Ishihara K, Mitchison TJ, Vale RD. Branching microtubule nucleation in Xenopus egg extracts mediated by augmin and TPX2. Cell. 2013 Ots 14;152(4):768-777.

48. Liska F, Gosele C, Rivkin E, Tres L, Cardoso MC, Domaing P, KrejciE,Snajdr P, Lee-irsch MA, de Rooij DG, Kren V, Krenova D, Kierszenbaum AL, Hubner N. Rat hd mutation reveals anessential role of centrobin in spermatid head shaping and assembly of the head-tail coupling apparatus. Biol Reprod. 2009 Abe;81(6):1196-11205.

49. Shin W, Yu NK, Kaang BK, Rhee K. The microtubule nucleation activity of centrobin in both the centrosome and cytoplasm. Cell Cycle. 2015;14(12):1925-1931.

50. Akhmanova A, Mausset-Bonnefont A-L, Cappellen W, Keijzer N, Hoogenraad CC, Stepanova T, Drabek K, Wees J, Mommaas M, Onderwater J. The microtubule plus-end-tracking protein CLIP170 associates with the spermatid manchette and is essential for spermatogenesis. Genes Dev. 2005 Urr 15;19(20):2501-2515.

51. Ashman JB, Hall ES, Eveleth J, Boekelheide K. Tau, the neuronal heat-stable microtubuleassociated protein, is also present in the cross-linked microtubule network of the testicular spermatid manchette. Biol Reprod. 1992 Urt;46(1):120-129.

52. Inoue H, Hiradate Y, Shirakata Y, Kanai K, Kosaka K, Gotoh A, Fukuda Y, Nakai Y, Uchida T, Sato E, Tanemura K. Site-specific phosphorylation of Tau protein is associated with deacetylation of microtubules in mouse spermatogenic cells during meiosis. FEBS Lett. 2014 Mai 29;588(11):20032008. 
53. Parysek LM., Wolosewick JJ, Olmsted JB. MAP 4: a microtubule-associated protein specific for a subset of tissue microtubules. J Cell Biol. 1984 Abe;99(6):2287-2296.

54. Penttila TL, Parvinen M. y Paranko J. Microtubule-associated epithelial protein E-MAP-115 is localized in the spermatid manchette. Int J Androl. 2003 Eka;26(3):166-174.

55. Walden PD, Cowan NJ. A novel 205-kilodalton testis-specific serine/threonine protein kinase associated with microtubules of the spermatid manchette. Mol Cell Biol. 1993 Abe;13(12):76257635.

56. Mendoza-Lujambio I, Burfeind P, Dixkens C, Meinhardt A, Hoyer-Fender S, Engel W, Neesen J. The Hook1 gene is non-functional in the abnormal spermatozoon head shape (azh) mutant mouse. Hum Mol Genet. 2002 Uzt 1;11(14):1647-1658.

57. Yamaguchi N, Takanezawa $Y$, Koizumi H, Umezu-Goto M, Aoki J, Arai H. Expression of NUDEL in manchette and its implication in spermatogenesis. FEBS Lett. 2004 Mai;566:71-76.

58. Nozawa YI, Yao E, Gacayan R, Xu SM, Chuang PT. Mammalian Fused is essential for sperm head shaping and periaxonemal structure formation during spermatogenesis. Dev Biol. 2014 Api 15;388(2):170-180.

59. Zheng H, Stratton CJ, Morozumi K, Jin J, Yanagimachi R, Yan W. Lack of Spem1 causes aberrant cytoplasm removal, sperm deformation, and male infertility. Proc Natl Acad Sci U S A. 2007 Api 17;104(16):6852-6857.

60. Yang WX, Sperry AO. C-Terminal Kinesin Motor KIFC1 Participates in Acrosome Biogenesis And Vesicle Transport. Biol Reprod. 2003 Aza;69(5):1719-1729.

61. Hayasaka S, Terada Y, Suzuki K, Murakawa H, Tachinaba I, Sankai T, Murakami T, Yaegashi N, Okamura K. Intramanchette transport during primate spermiogenesis: expression of dynein, myosin Va, motor recruiter myosin Va, VII-Rab27a/b interacting protein and Rab27b in the manchette during human and monkey spermiogenesis. Asian J Androl. 2008 Uzt;10(4):561-568.

62. Yang WX, Jefferson $H$, Sperry AO. The molecular motor KIFC1 associates with a complex containing nucleoporin NUP62 that is regulated during development and by the small GTPase Ran. Biol Reprod. 2006 Api;74(4):684-690.

63. O'Donnell L, O'Bryan MK. Microtubules and spermatogenesis. Semin Cell Dev Biol. 2014 Eka;30:45-54.

64. Chen SR, Batool A, Wang YQ, Hao XX, Chang CS, Cheng CY, Liu YX. The control of male fertility by spermatid-specific factors: searching for contraceptive targets from spermatozoon's head to tail. Cell Death Dis. 2016 Aza 10;7(11):e2472.

65. Zhou J, Du YR, Qin WH, Hu YG, Huang YN, Bao L, Han D, Mansouri A, Xu GL. RIM-BP3 is a manchette-associated protein essential for spermiogenesis. Development. 2009 Ots;136(3):373-82.

66. Pasek RC, Malarkey E, Berbari NF, Sharma N, Kesterson RA, Tres LL, Kierszenbaum AL, Yoder BK.Coiled-coil domain containing 42 (Ccdc42) is necessary for proper sperm development and male fertility in the mouse. Dev Biol. 2016 Api 15;412(2):208-218.

67. Fujimoto S, Yoshida N, Fukui T, Amanai M, Isobe T, Itagaki C, Izumi T, Perry AC. Mammalian phospholipase Czeta induces oocyte activation from the sperm perinuclear matrix. Dev Biol. 2004 Urr 15;274(2):370-383.

68. Swann K, Saunders CM, Rogers NT, Lai FA. PLC Zeta (zeta): a sperm protein that triggers Ca2p oscillations and egg activation in mammals. Semin Cell Dev Biol. 2006 Api;17(2):264-273.

69. Yoon SY, Fissore RA. Release of phospholipase $C$ zeta and [Ca2b]I oscillation-inducing activity during mammalian fertilization. Reproduction. 2007 Aza;134:695-704.

70. Grasa P, Coward K, Young C, Parrington J. The pattern of localization of the putative oocyte activation factor, phospholipase $C$ zeta, in uncapacitated, capacitated, and ionophore-treated human spermatozoa. Hum Reprod. 2008 Aza;23(11):2513-2522.

71. Escoffier J, Yassine S, Lee HC, Martinez G, Delaroch J, Coutton C, Karaouzene T, Zouari R, MetzlerGuillemain C, Pernet-Gallay K, Hennebicq S, Ray PF, Fissore R, Arnoult C. Subcellular localization of phospholipase $\mathrm{Cf}$ in human sperm and its absence in DPY19L2-deficient sperm are consistent with its role in oocyte activation. Mol Hum Reprod. 2015 Ots;21(2):157-168.

72. Sharma R, Agarwal A. Sperm Chromatin: Biological and Clinical Applications in Male Infertility and Assisted Reproduction. Springer Science; 2011.

73. Upadhyay Sushil K. Developmental biology and evolution. Vikas Publ House Pvt Ltd; 2019. 